\title{
EPO gene expression induces the proliferation, migration and invasion of bladder cancer cells through the p21WAF1-mediated ERK1/2/NF-кB/MMP-9 pathway
}

\author{
SUNG LYEA PARK $^{1}$, SE YEON WON ${ }^{1}$, JUN-HUI SONG ${ }^{1}$, WUN-JAE KIM ${ }^{2}$ and SUNG-KWON MOON ${ }^{1}$ \\ ${ }^{1}$ School of Food Science and Technology, Chung-Ang University, Anseong, Gyeonggi 456-756; \\ ${ }^{2}$ Personalized Tumor Engineering Research Center, Department of Urology, Chungbuk \\ National University, Cheongju, Chungbuk 361-763, Republic of Korea
}

Received June 12, 2014; Accepted August 6, 2014

DOI: $10.3892 /$ or.2014.3428

\begin{abstract}
Erythropoietin (EPO) is a cytokine that modulates the production of red blood cells. Previous studies have contradicted the assumed role of EPO in tumor cell proliferation. In the present study, we investigated the effect of EPO in the proliferation, migration and invasion that is involved in the signaling pathways and cell-cycle regulation of bladder cancer 5637 cells. The results showed that an overexpression of the EPO gene has a potent stimulatory effect on DNA synthesis, migration and invasion. EPO gene expression increased the expression of matrix metalloproteinase (MMP)-9 via the binding activity of NF- $\mathrm{KB}, \mathrm{AP}-1$ and Sp-1 in 5637 cells. The transfection of 5637 cells with the EPO gene induced the phosphorylation of ERK1/2. Treatment with ERK1/2 inhibitor U0126 significantly inhibited the increased proliferation, migration and invasion of EPO gene-transfected cells. U0126 treatment suppressed the induction of MMP-9 expression through NF- $\mathrm{KB}$ binding activity in EPO gene transfectants. In addition, EPO gene expression was correlated with the upregulation of cyclins/CDKs and the upregulation of the CDK inhibitor p21WAF1 expression. Finally, the inhibition of p21WAF1 function by siRNA blocked the proliferation, migration, invasion and phosphorylation of ERK1/2 signaling, as well as MMP-9 expression and activation of NF- $\mathrm{KB}$ in EPO gene-transfected cells. These novel findings suggest that the molecular mechanisms of EPO contribute to the progression and development of bladder tumors.
\end{abstract}

Correspondence to: Professor Sung-Kwon Moon, School of Food Science and Technology, Chung-Ang University, Anseong, Gyeonggi 456-756, Republic of Korea

E-mail: sumoon66@dreamwiz.com

Key words: bladder cancer, erythropoietin gene, proliferation, migration, invasion, p21WAF1

\section{Introduction}

In developed countries, bladder cancer is one of the most common forms of tumor that often lead to mortality in men (1). The proliferation and metastasis of bladder cancer cells plays an essential role in the development and progression of bladder tumors (2). The proliferation of bladder cancer cells has been definitively associated with the induction of multiple mitogen-activated protein kinases (MAPKs), including extracellular signal regulated kinase (ERK1/2), c-Jun NH2-terminal kinase (JNK), and p38 MAPK (p38) (3). In addition, it is widely accepted that the progression of the cell cycle is critical for the development and progression of bladder tumor cells $(4,5)$.

Tumor metastasis has been implicated in the migration and invasion of bladder cancer cells $(2,6,7)$. The expression of matrix metalloproteinase-9 (MMP-9) is known to be involved in the migration and invasion of bladder tumor cells $(2,6,7)$. Previous reports, based on in vitro and in vivo studies, have shown that MMP-9 is critical for the progression of bladder tumors via its regulation of both migration and invasion by bladder cancer cells $(2,6,7)$. Many studies have shown that MMP-9 expression is regulated primarily by transcription factors NF- $\mathrm{kB}, \mathrm{AP}-1$, and Sp-1 (7-10). Recent studies have shown that MAPKs are connected to the expression of MMP-9 in bladder cancer cells via the activation of NF- $\kappa B$ and AP-1 (7,11).

Human erythropoietin (EPO) plays a role in the control of red blood cell production $(12,13)$. EPO stimulates the activation of JAK2/STAT5, MAPKs, phosphatidylinositol 3-kinase (PI3K), and Akt signaling through the binding of human erythropoietin receptor (EPOR) (14). Several studies have shown that the exogenous treatment of EPO and the overexpression of EPOR stimulate proliferation, migration and invasiveness in various cell types (15-19). On the other hand, other reports have not associated EPO with a proliferative effect on cancer cells (20-22). Although many studies have investigated the role of EPO in cancer cells, the precise molecular mechanisms underlying the cell-cycle regulation and signaling pathways that are linked with cell proliferation, migration and invasion of cancer cells remain unclear.

Recently, we found an upregulated gene expression level of EPO in bladder tumor patients using microarray expression 
analysis (23). The purpose of the present study was to determine the role and regulatory mechanisms of the EPO gene in bladder cancer cells. In this study, we identified a novel mechanism of cell-cycle inhibitor p21WAF1 for the induction of proliferation, migration and invasion in EPO gene expression in bladder cancer cells.

\section{Materials and methods}

Materials. Polyclonal antibodies to ERK, phospho-ERK, p38MAPK, phospho-p38MAPK, JNK, and phospho-JNK were obtained from Cell Signaling (Danvers, MA, USA). Polyclonal antibodies to cyclin E, CDK2, CDK4, cyclin D1, p53, p21WAF1, p27KIP1 and GAPDH were purchased from Santa Cruz (Santa Cruz, CA, USA). U0126 was obtained from Calbiochem (San Diego, CA, USA). Polyclonal MMP-9 antibody was obtained from Chemicon (Temecula, CA, USA). Small interfering RNA (siRNA) oligonucleotides targeting p21WAF1 and scramble were designed and synthesized by Dharmacon (Lafayette, CO, USA). pcDNA3-EPO plasmid containing human wild-type full-length EPO was generously provided by Dr Taiho Kambe (Kyoto University, Japan).

Cell cultures. A human bladder carcinoma cell line (5637) was obtained from the American Type Culture Collection. The cells were maintained in DMEM ( $4.5 \mathrm{~g}$ glucose/liter) and were supplemented with $10 \%$ fetal calf serum, L-glutamine, and antibiotics (Biological Industries, Beit Haemek, Israel) at $37^{\circ} \mathrm{C}$ in a $5 \% \mathrm{CO}_{2}$ humidified incubator.

Cell transfection. 5637 cells were transfected with pcDNA3EPO (EPO) or pcDNA3 (no insert, EV) in 100-mm dishes using the Superfect reagent (Qiagen, Valencia, CA, USA) according to the manufacturer's protocol. After $24 \mathrm{~h}$, cells were split at a 1:5 dilution and exposed for 2-3 weeks in G418 (Boehringer Mannheim, Indianapolis, IN, USA)-containing medium $(800 \mu \mathrm{g} / \mathrm{ml})$, and the resultant colonies were selected based on their resistance to G418. The expression of EPO was confirmed by immunoblot analysis using a monoclonal antibody against EPO (R\&D Systems).

$\left[{ }^{3} H\right]$ thymidine incorporation. For $\left[{ }^{3} \mathrm{H}\right]$ thymidine-uptake experiments, cells were grown to near confluence in 24-well tissue culture plates and were then labeled with [methyl- $\left.{ }^{3} \mathrm{H}\right]$ thymidine (New England Nuclear, Boston, MA, USA) at $1 \mu \mathrm{Ci} / \mathrm{ml}$. After labeling, the cells were cultured for $24 \mathrm{~h}$ and washed with phosphate-buffered saline, fixed in cold $10 \%$ trichloroacetic acid, then washed with $95 \%$ ethanol. Incorporated $\left[{ }^{3} \mathrm{H}\right]$ thymidine was extracted in $0.2 \mathrm{M} \mathrm{NaOH}$ and measured using a liquid scintillation counter as previously described (24).

Immunoblotting. The cells were incubated with 10\% FBS for various durations at $37^{\circ} \mathrm{C}$. The cells were then washed twice with cold PBS and freeze-thawed in $250 \mu 1$ lysis buffer [containing, in mmol/1, HEPES (pH 7.5) 50, NaCl 150, EDTA 1, EGTA 2.5, DTT $1, \beta$-glycerophosphate $10, \mathrm{NaF} 1, \mathrm{Na}_{3} \mathrm{VO}_{4} 0.1$, and phenylmethylsulfonyl fluoride 0.1 and $10 \%$ glycerol, $0.1 \%$ Tween-20, $10 \mu \mathrm{g} / \mathrm{ml}$ of leupeptin, and $2 \mu \mathrm{g} / \mathrm{ml}$ of aprotinin], and then scraped into $1.5-\mathrm{ml}$ tubes. The lysates were placed on ice for
$15 \mathrm{~min}$ and then centrifuged at $12,000 \mathrm{rpm}$ for $20 \mathrm{~min}$ at $4^{\circ} \mathrm{C}$. The protein concentration of the supernatant was determined using the Bradford reagent method (Bio-Rad). Equal amounts of cellular proteins were resolved by electrophoresis on a $0.1 \%$ SDS-10\% polyacrylamide gel (SDS-PAGE) under denaturing conditions. The proteins were transferred electrophoretically to nitrocellulose membranes (Hybond; Amersham Corp). After blocking in $10 \mathrm{mmol} / \mathrm{l}$ Tris- $\mathrm{HCl}(\mathrm{pH} 8.0), 150 \mathrm{mmol} / \mathrm{l} \mathrm{NaCl}$, and $5 \%(\mathrm{wt} / \mathrm{vol})$ nonfat dry milk, the membranes were treated with primary antibodies for $90 \mathrm{~min}$, followed by incubation with peroxidase-conjugated secondary antibodies for $45 \mathrm{~min}$. The immune complexes were detected using a chemiluminescence reagent kit (Amersham Corp.). For the immunoblotting studies, the experiments were repeated at least 3 times.

Immunoprecipitation and immune complex kinase assays. Cell lysates were prepared with ice-cold lysis buffer [containing, in mM/1, HEPES (pH 7.5) 50, NaCl 150, EDTA 1, EGTA 2.5 , DTT $1, \beta$-glycerophosphate $10, \mathrm{NaF} 1, \mathrm{Na}_{3} \mathrm{VO}_{4} 0.1$, and phenylmethylsulfonyl fluoride 0.1 and $10 \%$ glycerol, $0.1 \%$ Tween-20,10 $\mu \mathrm{g} / \mathrm{ml}$ of leupeptin, and $2 \mu \mathrm{g} / \mathrm{ml}$ of aprotinin] and sonicated at $4^{\circ} \mathrm{C}$ [Micro ultrasonic cell disruptor (Kontes), $30 \%$ power, twice for $10 \mathrm{sec}$ each time]. Lysates were clarified by centrifugation at $10,000 \mathrm{xg}$ for $5 \mathrm{~min}$, and the supernatants were precipitated by treatment with protein A-Sepharose beads precoated with saturating amounts of the indicated antibodies at $4^{\circ} \mathrm{C}$ for $2 \mathrm{~h}$. When monoclonal antibodies were used, protein A-Sepharose was pretreated with rabbit anti-mouse immunoglobulin G (Jackson Immuno Research Laboratories). The immunoprecipitated proteins on the beads were washed 4 times with $1 \mathrm{ml}$ of lysis buffer and twice with a kinase buffer (containing, in $\mathrm{mM} / \mathrm{l}$, HEPES $50, \mathrm{MgCl}_{2} 10$, DTT 1 , $\beta$-glycerophosphate $10, \mathrm{NaF} 1$, and sodium orthovanadate 0.1 ). The final pellet was resuspended in $25 \mu$ l of kinase buffer containing either $1 \mu \mathrm{g}$ of glutathione S-transferase (GST)-pRb C-terminal (pRb amino acids 769 to 921) fusion protein (Santa Cruz Biotechnology) or $5 \mu \mathrm{g}$ of histone H1 (Life Technologies, Inc.), $20 \mu \mathrm{M} / 1 \mathrm{ATP}$, and $5 \mu \mathrm{Ci}$ of $\left[\gamma^{32} \mathrm{P}\right] \mathrm{ATP}(4,500 \mu \mathrm{Ci} / \mathrm{mmol}$; ICN), and were then incubated for $20 \mathrm{~min}$ at $30^{\circ} \mathrm{C}$ with occasional mixing. The reaction was terminated by the addition of $25 \mu \mathrm{l}$ of $2 \mathrm{X}$ concentrated Laemmli sample buffer and separated on either 10 or $12.5 \%$ SDS-polyacrylamide gels. The migration of histone H1 or GST-pRb was determined by Coomassie blue staining. Phosphorylated $\mathrm{pRb}$ and histone $\mathrm{H} 1$ were visualized.

Wound-healing migration assay. Cells were plated on 6-well dishes and grown to $90 \%$ confluency in $2 \mathrm{ml}$ of growth medium. The cells were damaged using a 2-mm-wide tip. They were allowed to migrate, and images were captured through an inverted microscope (magnification, $\mathrm{X} 40$ ).

Invasion assay. Cells $\left(2.5 \times 10^{4}\right)$ were resuspended with $100 \mu \mathrm{l}$ of medium and placed in the upper part of a Transwell plate. The cells were then incubated for $24 \mathrm{~h}$. The cells had to pass through a polycarbonate membrane with $8-\mu \mathrm{m}$-sized pores and a thin layer of an ECM Matrix-like material. The ability of the cells to invade the ECM Matrix-like material was determined using a commercial cell invasion assay kit (Chemicon International, Billerica, MA, USA). 
A

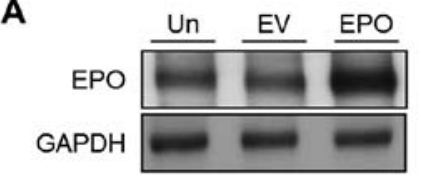

B

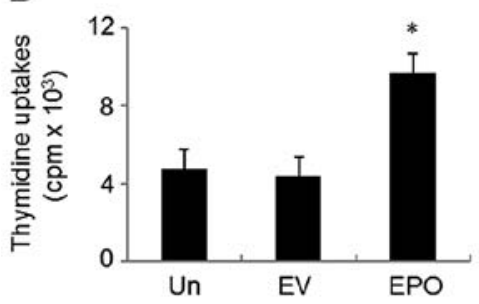

C

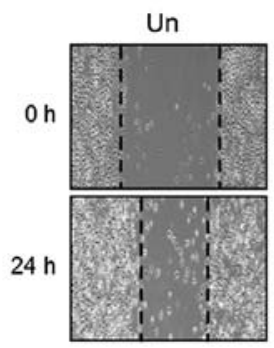

D

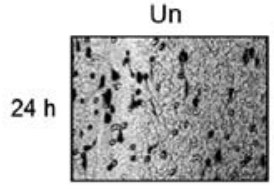

EV

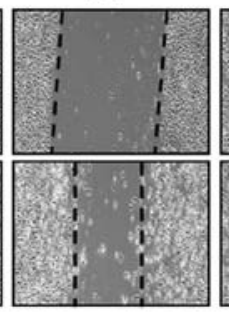

EV

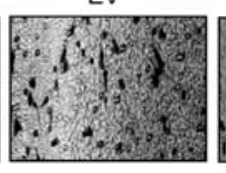

EPO

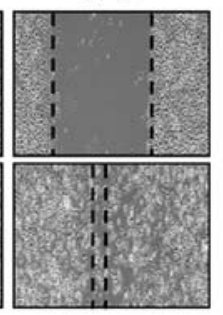

F
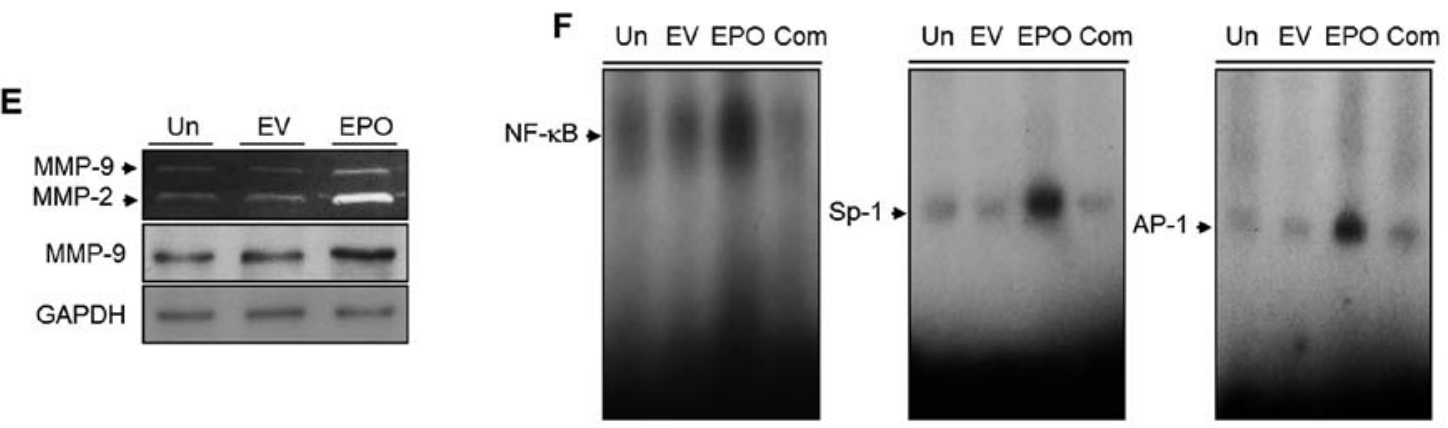

Figure 1. EPO gene expression induces the proliferation, migration and invasion of bladder cancer 5637 cells. (A) Expression of the EPO in parental cells (Un), vector control cells (EV) and cells stably expressing the EPO gene (EPO). Cell lysates from the indicated cell lines were performed by immunoblot analysis with anti-EPO antibody. The results were normalized to GAPDH expression. (B) Indicated cells were grown normally and labeled with [methyl $\left.-{ }^{3} \mathrm{H}\right]$ thymidine during the last $24 \mathrm{~h}$ of this time period. Thymidine incorporation was examined by scintillation counting of precipitated DNA. Results are analyzed as the means \pm SE from three triplicate experiments. ${ }^{*} \mathrm{P}<0.01$ compared with EV. (C) Confluent cells were wounded with a pipette tip. After 24 h, wound closure rates were examined under a phase contrast microscope. (D) Indicated cells were cultured in Boyden chambers. Invasion assay was used to assess the ability of cells to invade through matrigel. (E) Indicated cells were incubated for $24 \mathrm{~h}$. The supernatant and cell lysates were used to analyze MMP-9 expression by zymography and immunoblot, respectively. (F) Indicated cells were incubated for 24 h. EMSA assay was analyzed for the NF- $\kappa$ B, AP-1 and Sp-1 using

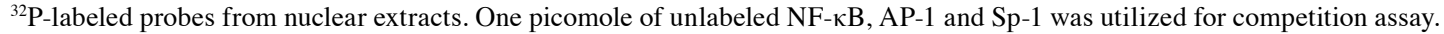

Zymography. Conditioned medium was electrophoresed in a polyacrylamide gel containing $1 \mathrm{mg} / \mathrm{ml}$ gelatin. The gel was then washed at room temperature for $2 \mathrm{~h}$ with $2.5 \%$ Triton X-100 and subsequently incubated at $37^{\circ} \mathrm{C}$ overnight in a buffer containing $10 \mathrm{mM} \mathrm{CaCl}_{2}, 150 \mathrm{mM} \mathrm{NaCl}$, and $50 \mathrm{mM}$ Tris- $\mathrm{HCl}, \mathrm{pH}$ 7.5. The gel was stained with $0.2 \%$ Coomassie blue and photographed on a light box. Proteolysis was detected as a white zone in a dark blue field $(7,9,24)$.

Nuclear extracts and electrophoretic mobility shift assay (EMSA). Cultured cells were collected by centrifugation, washed and suspended in a buffer containing $10 \mathrm{mM}$ Hepes ( $\mathrm{pH} 7.9)$, $10 \mathrm{mM} \mathrm{KCl}, 0.1 \mathrm{mM}$ EDTA, $0.1 \mathrm{mM}$ EGTA, $1 \mathrm{mM}$ DTT, and $0.5 \mathrm{mM}$ PMSF. After $15 \mathrm{~min}$ on ice, the cells were vortexed in the presence of $0.5 \%$ Nonidet NP-40. The nuclear pellet was then collected by centrifugation and extracted in a buffer containing $20 \mathrm{mM}$ Hepes pH 7.9, 0.4 M NaCl, $1 \mathrm{mM}$ EDTA, $1 \mathrm{mM}$ EGTA, $1 \mathrm{mM}$ DTT, and $1 \mathrm{mM}$ PMSF for $15 \mathrm{~min}$ at $4^{\circ} \mathrm{C}$.

The nuclear extract $(10-20 \mu \mathrm{g})$ was preincubated at $4^{\circ} \mathrm{C}$ for $30 \mathrm{~min}$ with a 100 -fold excess of an unlabeled oligonucleotide spanning the -79 MMP-9 cis element of interest. The sequences were: AP-1, CTGACCCCTGAGTCAGCACTT; NF- $\kappa$, CAGTGGAATTCCCCAGCC; and Sp-1, GCCCATT CCTTCCGCCCCCAGATGAAGCAG. The reaction mixture was then incubated at $4^{\circ} \mathrm{C}$ for $20 \mathrm{~min}$ in a buffer $(25 \mathrm{mM}$
HEPES buffer pH 7.9, 0.5 mM EDTA, 0.5 mM DTT, 0.05 M $\mathrm{NaCl}$, and $2.5 \%$ glycerol) with $2 \mu \mathrm{g}$ of poly $\mathrm{dI} / \mathrm{dC}$ and $5 \mathrm{fmol}$ $\left(2 \times 10^{4} \mathrm{cpm}\right)$ of a Klenow end-labeled $\left({ }^{32} \mathrm{P}-\mathrm{ATP}\right) 30$-mer oligonucleotide, which spanned the DNA binding site in the MMP-9 promoter. The reaction mixture was electrophoresed at $4{ }^{\circ} \mathrm{C}$ in a $6 \%$ polyacrylamide gel using a TBE ( $89 \mathrm{mM}$ Tris, $89 \mathrm{mM}$ boric acid and 1 mM EDTA) running buffer. The gel was rinsed with water, dried and exposed to X-ray film overnight $(7,9,24)$.

Statistical analysis. Where appropriate, data are expressed as the mean \pm SE. Data were analyzed by factorial ANOVA and a Fisher's least significant difference test where appropriate. Statistical significance was set at $\mathrm{P}<0.05$.

\section{Results}

EPO gene overexpression induces DNA synthesis, migration and invasion of bladder cancer 5637 cells. To investigate the role of EPO in the proliferation, migration and invasion of cancer cells, bladder cancer 5637 cells were transfected with an EPO cDNA (EPO) or an identical empty vector lacking a cDNA insert as a control (EV). Stable cell clones (EPO) were isolated, and parental cells (UN) were used as an additional control. Validation of the EPO gene was evaluated by immunoblotting (Fig. 1A). Cells expressing EPO showed an 
A
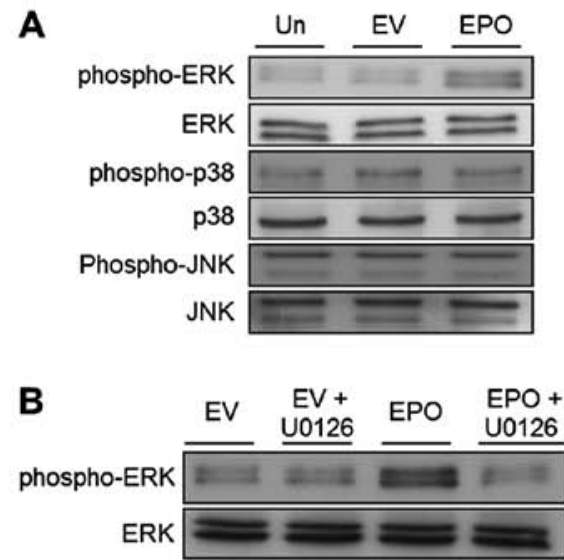

C

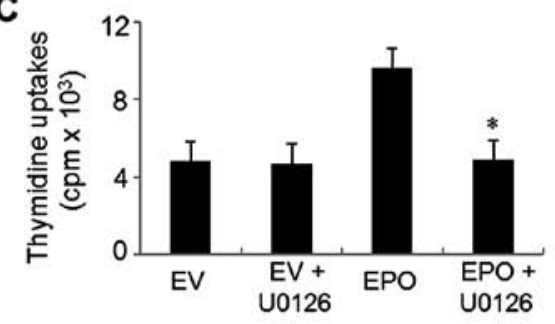

F

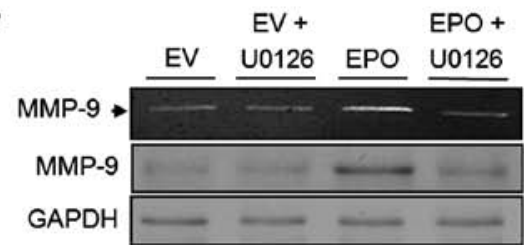

D

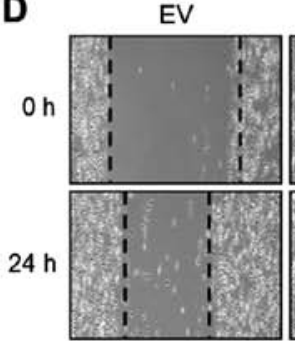

$E V+U 0126$
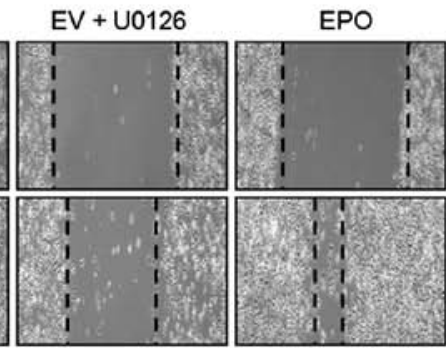

$E P O+U 0126$

E

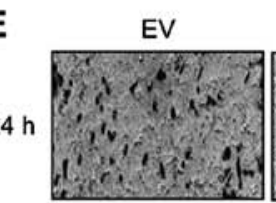

$\mathrm{EV}+\mathrm{U} 0126$

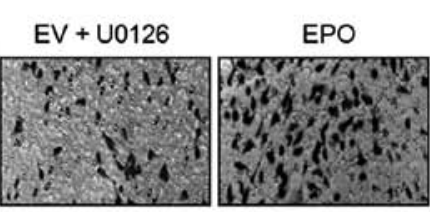

$\mathrm{EPO}+\mathrm{U} 0126$

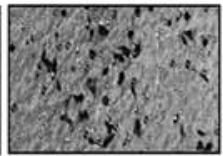

G
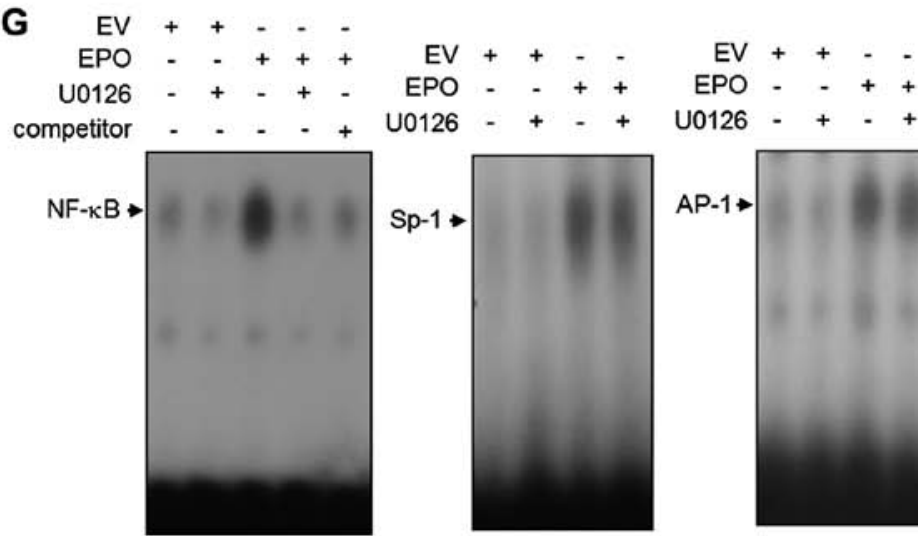

$\mathrm{U} 0126-+\cdot+$

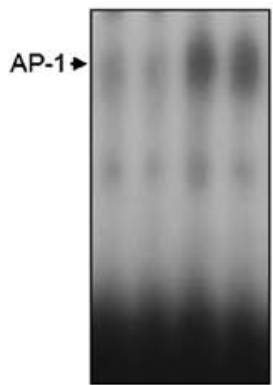

Figure 2. Inhibition of ERK1/2 phosphorylation suppresses the induction of proliferation, migration, invasion and NF- $\mathrm{BB}$-mediated MMP-9 expression in EPO gene-transfected cells. Cells were cultured in the presence or absence of U0126 (10 $\mu \mathrm{M})$ for $24 \mathrm{~h}$. (A and B) Immunoblot analysis was then performed with phospho-ERK1/2, ERK1/2, phospho-p38, p38, phospho-JNK, JNK and GAPDH using cell lysates. (C) Incorporation of thymidine uptakes was measured by scintillation counting of precipitated DNA. Results are expressed as the means \pm SE from three triplicate experiments. "P<0.01 compared with EPO. (D and E) The capacity of wound-healing migration and invasion was analyzed, as described in Materials and methods. (F) Production of MMP-9 in culture supernatants was measured by gelatin zymography. MMP-9 expression from cell lysates was analyzed by immunoblot. (G) Nuclear proteins were extracted. Binding activity of NF- $\mathrm{kB}, \mathrm{Sp}-1$ and AP-1 was examined by EMSA using radiolabeled oligonucleotide probes. The competition assay was performed by one picomole of unlabeled NF-kB.

2.1-fold increase in $\left[{ }^{3} \mathrm{H}\right]$ thymidine incorporation, compared to UN and EV transfectants (Fig. 1B). We then investigated the effect of the EPO gene on the migratory and invasive capacity of bladder cancer 5637 cells using a wound-healing migration and invasion assay system. Compared with UN and EV transfectants, EPO gene transfectants significantly increased the migratory and invasive potential of cells (Fig. 1C and D).

EPO gene transfectants stimulate MMP-9 expression via the activation of transcription factor $N F-\kappa B, S p-1$ and AP-1. Gelatinolytic zymography assay was employed to study the systemic mechanism of the migration and invasion of 5637 cells expressing EPO. Compared with that of the UN, the conditioned media from the EPO gene transfectant cells induced the upregulation of MMP-9 gelatinolytic activity (Fig. 1E). In addition, EV transfectants had no effect on MMP-9 activity (Fig. 1E). Similar results were detected in immunoblot analysis (Fig. 1E). To determine whether the stimulatory effect of the EPO gene on MMP-9 expression was mediated through three types of motifs, NF- $\kappa$ B, Sp-1, and AP-1 activation, EMSA was next performed with the nuclear extracts of UN, EV transfectant and EPO gene transfectant cells. Nuclear extracts from EPO gene transfectants showed increased binding activities of the NF- $\mathrm{BB}, \mathrm{Sp}-1$ and AP-1 motifs (Fig. 1F). However, neither the EV transfectants nor that of the UN had any effect on NF- $\mathrm{KB}, \mathrm{Sp}-1$ or AP-1 binding activities (Fig. 1F).

EPO gene transfectants stimulate the phosphorylation of ERK1/2 in 5637 cells. To assess the effect of the signaling pathways involved in the proliferation of EPO gene transfectants, ERK1/2, p38MAPK and JNK phosphorylations were analyzed. As shown in Fig. 2A, the overexpression of the EPO gene induced an increased phosphorylation of ERK1/2. In addition, pre-treatment with U0126 (ERK1/2-specific inhibitor) suppressed ERK1/2 phosphorylation in EPO gene transfectant cells (Fig. 2B). However, EPO gene transfectants did not stimulate p38MAPK and JNK phosphorylation (Fig. 2A).

U0126 inhibits the potential for proliferation, migration, and invasion in EPO gene transfectants. Since the overexpression of EPO stimulated ERK1/2 phosphorylation, we investigated the role of ERK1/2 in the EPO-stimulated proliferation, 
A

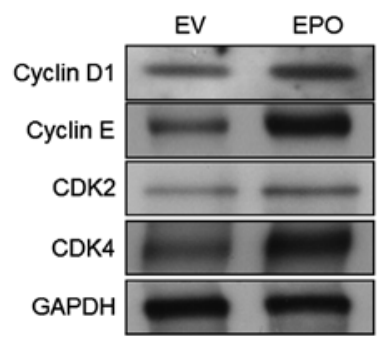

C

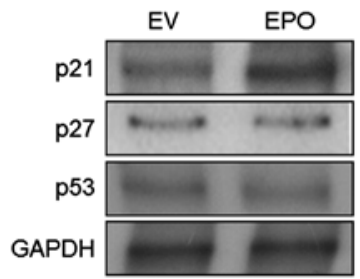

D

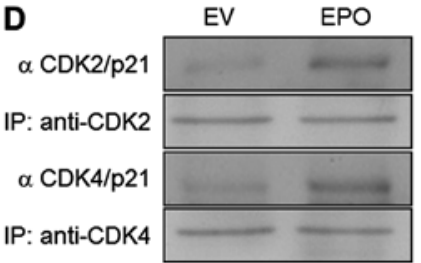

Figure 3. EPO gene expression stimulates the expression of cyclin D1, cyclin E, CDK2, CDK4 and p21WAF1 in 5637 cells. Indicated cells were incubated for $24 \mathrm{~h}$. (A and C) The cells were analyzed for the specific antibodies cyclin D1, cyclin E, CDK2, CDK4, p21WAF1, p27KIP1, and p53 by immunoblot analysis. The expression level of GAPDH was used as a loading control. (B) The immunoprecipitation was performed with anti-CDK2 and anti-CDK4 antibodies using total cell lysates. The kinase reaction was analyzed by histone H1 (for CDK2) or GST-RB (for CDK4) as a substrate. (D) Equal amounts of cell lysates were immunoprecipitated with anti-CDK2 and anti-CDK4 antibodies. The immunoprecipitates were subjected to immunoblot analysis with an anti-p21WAF1 antibody. The relative expression level of immunoprecipitated CDK2 and CDK4 was used as a loading control.

migration and invasion of 5637 cells. The increased cell proliferation after EPO gene transfection was strongly reversed in the presence of U0126 (Fig. 2C). In addition, treatment with U0126 blocked the EPO-induced wound healing migration and invasion of 5637 cells (Fig. 2D and E). Moreover, the U0126 treatment reversed MMP-9 gelatinolytic activity in the conditioned media from EPO gene transfectant cells to the level of EV transfectants (Fig. 2F). Similar results were observed in immunoblot analysis (Fig. 2F). To further verify the regulatory mechanism of MMP-9 expression, we next performed an EMSA experiment. As shown in Fig. 2G, the increased NF- $\kappa B$ binding activation in EPO gene transfectants was reversed to basal levels of EV transfectants in the presence of U0126. By contrast, U0126 treatment had no significant effect on the binding activity of Sp-1 and AP-1 in EPO gene transfectants (Fig. 2G).

EPO gene transfectants modulate G1 cell-cycle-associated proteins and induce $21 W A F 1$ expression. To verify that the observed growth stimulatory effects of EPO gene transfectants were involved in the increased expression of cell-cycle machinery, the levels of cell-cycle machinery molecules were investigated. The expression levels of the G1-associated factors, cyclin D1/CDK4 and cyclin E/CDK2, were upregulated in EPO gene transfectants by comparison with the EV transfectants (Fig. 3A). In addition, overexpression of the EPO gene resulted in a significant increase in the kinase activities of both CDK2- and CDK4-immunoprecipitates compared with the EV transfectant cells (Fig. 3B). Since the cell-cycle inhibitors are known to regulate the G1- to S-phase transition checkpoints, the expression levels of p21WAF1 and p27KIP1 were assessed in both EPO gene transfectants and EV transfectants. Notably, the results showed that p21WAF1 levels were increased in EPO gene-transfected cells compared with EV-transfected cells (Fig. 3C). However, under similar experimental conditions, the expression of p27KIP1 was unaffected (Fig. 3C). Moreover, the overexpression of the EPO gene had no effect on the induction of the tumor suppressor protein p53 (Fig. 3C). We next examined the effects of the EPO gene on interactions between p21WAF1 and CDKs. Immunoprecipitation analysis revealed that the EPO gene transfectants exhibited a strong increase in the association of p21WAF1 and CDK2 compared with the EV transfectants (Fig. 3D). The binding of p21WAF1 and CDK4 was also increased in the EPO gene transfectants (Fig. 3D).

siRNA-mediated knockdown of p21WAF1 restores the proliferation, migration, invasion, MMP-9 expression, ERK1/2 phosphorylation and binding activity of $N F-\kappa B$ in the EPO gene transfectants. To determine the effect of inhibiting the p21WAF1 expression in EPO gene transfectants, we used either a p21WAF1-specific siRNA (si-p21) or a scrambled siRNA. The expression level of p21WAF1 was determined by immunoblot analysis (Figs. 4F and 5F). As shown in Fig. 4A and B, EPO gene transfectants of si-p21 suppressed the increase in proliferation and ERK1/2 phosphorylation. EPO-induced wound-healing migration and invasive ability was also reversed in the presence of si-p21 transfection (Fig. 4C and D). In addition, the upregulation of MMP-9 expression was abolished in EPO cells transfected with si-p21, as evidenced by gelatin zymography and immunoblot analysis (Fig. 4A).

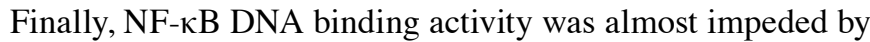
the transfection of si-p21 in EPO gene transfectants (Fig. 4E). EPO gene transfectants had no significant effect on the proliferation, migration, invasion, MMP-9 expression, ERK1/2 phosphorylation and binding activity of $N F-\kappa B$ in the presence of scrambled siRNA transfection (Fig. 5A-E).

\section{Discussion}

In a previous study, our gene expression profile data produced by cDNA microarray experimentation showed that the expression levels of the EPO gene were increased in patients with 
A

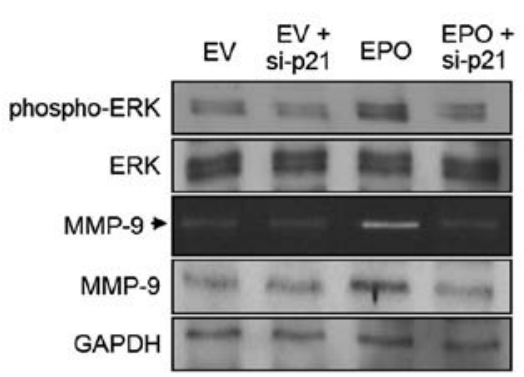

B

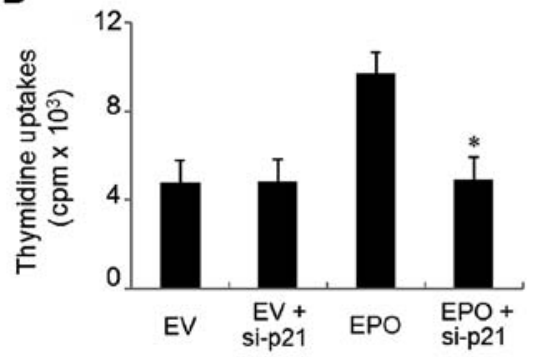

C
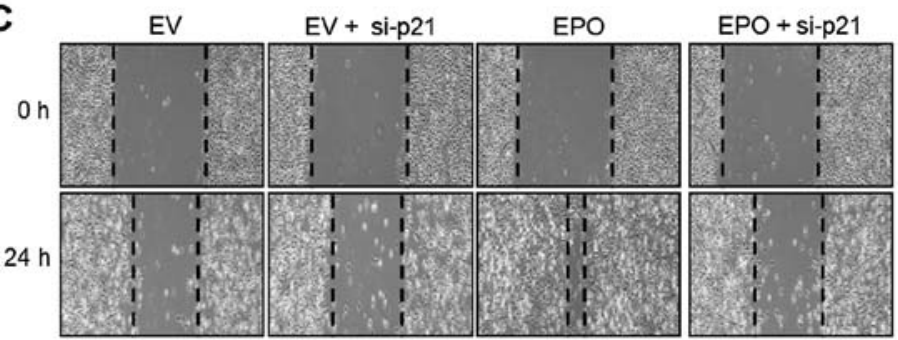

D

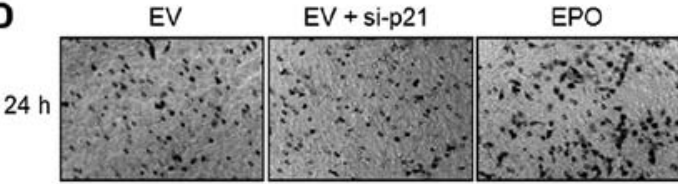

E

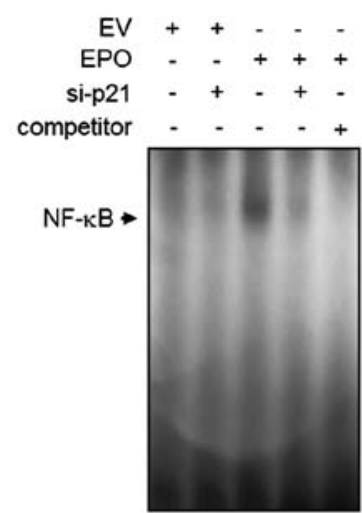

F

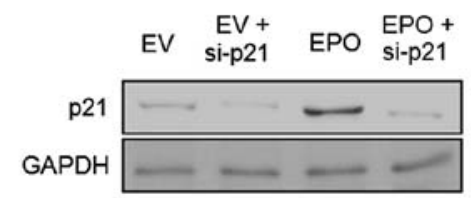

Figure 4. The involvement of p21WAF1 in the proliferation, migration, invasion, ERK1/2 phosphorylation and NF- $\kappa \mathrm{B}-\mathrm{mediated} \mathrm{MMP}-9$ expression in EPO gene-transfected 5637 cells. (A) Indicated cells were transfected with si-p21 for $24 \mathrm{~h}$, MMP-9 expression was examined from culture supernatants and cell lysates using the zymographic and immunoblot analysis. The phosphorylation of ERK1/2 was assessed by performing immunoblot analysis from cell lysates. (B) After transfection of si-p21 with indicated cells for $24 \mathrm{~h}$, thymidine incorporation was analyzed to examine the level of cell proliferation. Results are recorded as the means \pm SE from three triplicate experiments. ${ }^{*} \mathrm{P}<0.01$ compared with EPO. (C and D) Indicated cells were transfected with si-p21. After $24 \mathrm{~h}$, wound-healing migration and invasion assay was performed as described in Materials and methods. (E) EMSA assay was used to analyze the binding activity

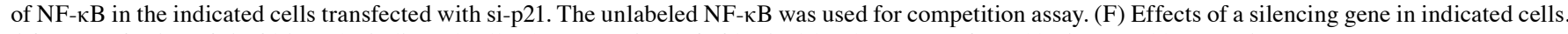
After transfection of si-p21 into the indicated cells, the expressions of p21WAF1 levels were confirmed by immunoblot experiment.

bladder tumors (23). In the present study, we suggest a novel role for the EPO gene that is involved in the p21WAF1-mediated proliferation, migration and invasion of bladder cancer 5637 cells.

In the past few years, a number of studies on the modulation of cell proliferation and migration by EPO have been conducted (15-19). Published evidence has indicated that EPO may be involved in the differentiation of erythroid progenitor cells in vitro (12-14). However, previous studies have also shown that EPO did not stimulate the growth of tumor cell lines (20-22). In the present study, transfection of the EPO gene into bladder cancer 5637 cells resulted in increased thymidine uptake at the basal level. In addition, overexpression of the EPO gene induced the migration and invasion of 5637 cells. Consistent with our present results, several studies have reported that exogenous EPO or EPO gene expression induced the proliferation, migration and invasion of cancer cell lines (15-19). These results suggest that overexpression of the EPO gene is involved in the induction of the proliferation, migration and invasion of bladder cancer 5637 cells.

The elevated level of MMP-9 expression was strongly associated with the progression and migration of bladder cancer in animal and clinical studies $(2,6,7)$. In results from the present study, overexpression of the EPO gene stimulated an enhanced level of MMP-9 expression. Moreover, we analyzed the transcriptional regulation of MMP-9 in 5637 cells expressing the EPO gene, and found that it promoted MMP-9 expression via the increased binding activation of $\mathrm{NF}-\kappa \mathrm{B}, \mathrm{Sp}-1$ and AP-1 in 5637 cells. These results suggest that the EPO induced the expression of MMP-9 via the activation of NF- $\mathrm{B}, \mathrm{Sp}-1$ and AP-1 in 5637 cells, which caused the destruction of ECM and influenced the migration and invasion of bladder cancer progression.

Since transfection of the EPO gene into 5637 cells resulted in increased thymidine uptake, we next investigated the MAPK signaling pathways, including ERK1/2, JNK, and p38 MAPK, in EPO gene transfectants. Many studies have suggested the stimulatory effects of EPO on ERK1/2 phosphorylation in several lines of cells $(14,18)$. Consistent with the results of previous studies, in the present study EPO gene expression induced ERK1/2 phosphorylation without altering the phosphorylation of either JNK or p38MAPK. In addition, an inhibitor of the ERK1/2 signaling molecule U0126 inhibited the proliferation, migration and invasion of cells transfected by the EPO gene. Moreover, U0126 suppressed both the expression of MMP-9 and the activation of $N F-\kappa B$ in EPO gene 
A

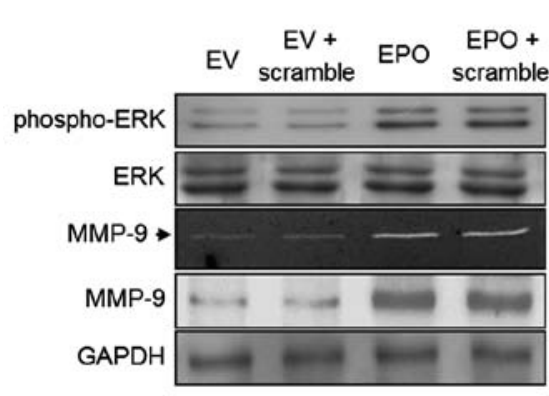

B

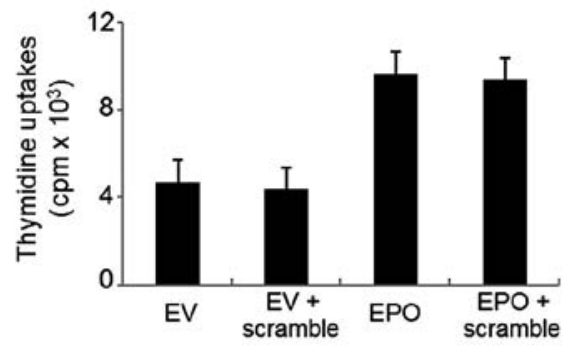

C

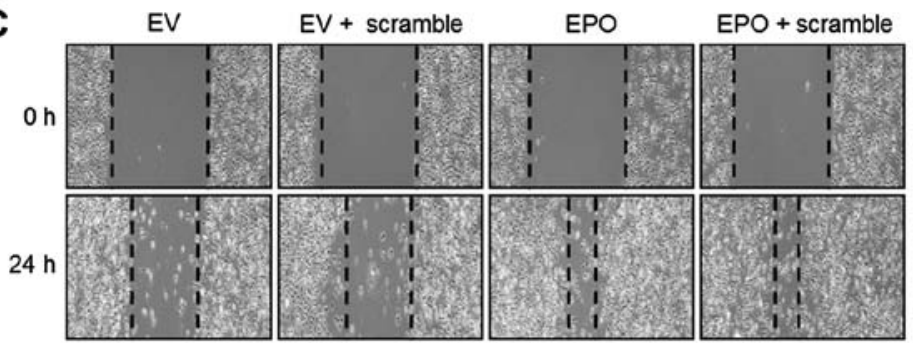

D

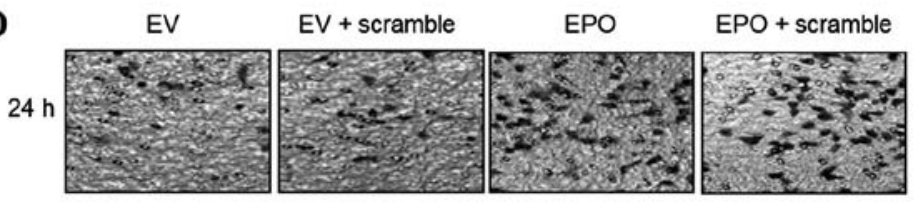

E

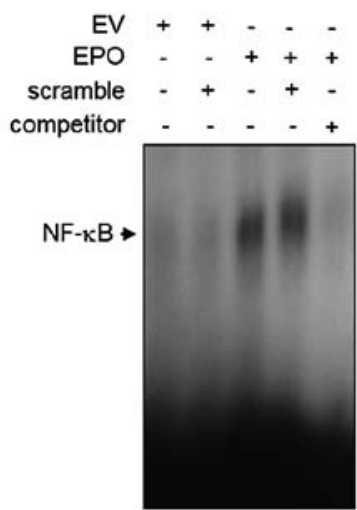

F

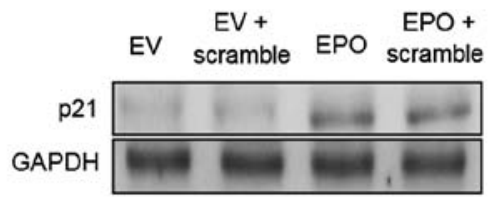

Figure 5. The effect of scramble siRNA in EPO gene-stimulated proliferation, migration, invasion, ERK1/2 phosphorylation and NF- $\kappa \mathrm{B}-\mathrm{mediated} \mathrm{MMP}-9$ expression in 5637 cells. Indicated cells were transfected with scramble siRNA for $24 \mathrm{~h}$. (A) Culture supernatants and cell lysates were analyzed to determine the expression of MMP-9 using zymographic and immunoblot analysis. The phosphorylation of ERK1/2 in scramble siRNA transfected cells was analyzed from cell lysates using immunoblot analysis. (B) Thymidine uptake was used to examine the proliferation of indicated cells transfected with scramble siRNA. Indicated values are the means of triplicate wells. (C and D) Migratory and invasive potential of indicated cells transfected with scramble siRNA were performed by wound-healing migration and invasion assay as described in Materials and methods. (E) Nuclear extracts were isolated, and activation of NF- $\mathrm{B}$ binding motif was analyzed by EMSA with radiolabeled oligonucleotide probes. The competition assay was utilized using one picomole of unlabeled NF- $\kappa \mathrm{B}$. (F) Indicated cells transfected with scrambled siRNA were confirmed by immunoblot experiment for p21WAF1 expression.

transfectants. Our results demonstrated that ERK1/2 signaling is involved in the proliferation, migration and invasion of EPO gene-expressed 5637 cells. We also found that transcription factor $\mathrm{NF}-\kappa \mathrm{B}$ is important in the ERK1/2-mediated regulation of MMP-9 expression in 5637 bladder cancer cells expressing the EPO gene.

The G1- to S-phase cell-cycle progression is a key event in the progression and development of tumor cells $(25,26)$. The G1- to S-phase transition is regulated by cyclin-dependent kinases(CDKs), including cyclin D1/CDK4 and cyclin E/CDK2, which are negatively controlled via the binding of CDK inhibitors (CKIs) such as p21WAF1 and p27KIP1 $(25,26)$. Several studies have suggested the involvement of EPO in cell-cycle regulators during the differentiation of erythroid progenitor cells and the proliferation of hematopoietic cells $(27,28)$. However, the molecular regulation of cell-cycle regulators coordinated with the proliferation, migration and invasion of tumor cells merits further investigation. Therefore, we examined the effect of the EPO gene on CDK and CKI levels responsible for the G1 to $\mathrm{S}$ transition. Results of the present study showed that overexpression of the EPO gene in 5637 cells significantly upregulated cyclin D1, cyclin E, CDK2 and CDK4, along with the stimulation of CDK4 and CDK2 kinase activity. Notably, our data also showed a significantly elevated level of p21WAF1, but not of p27KIP1 and p53. To further elucidate how p21WAF1 modulates cell proliferation, migration and invasion in EPO gene transfectants, we conducted a specific siRNA knockdown experiment using p21WAF1 (si-p21). Our data suggest the novel theory that p21WAF1 is indispensable for the proliferation, migration and invasion of 5637 cells in response to the EPO gene. Our results further enhanced these findings by demonstrating that p21WAF1 regulated ERK/1/2coordinated MMP-9 expression via upregulated $N F-\kappa B$ binding in the EPO gene-induced proliferation, migration and invasion of bladder cancer 5637 cells.

Many studies have demonstrated that p21WAF1 is a negative regulator in the control of cell-cycle progression $(25,26)$, but previous studies have suggested that it is a positive modulator in the proliferation and migration of several cell lines $(7,23,25,26)$. Several studies now associate p21WAF1 with clinical evidence that shows involvement in bladder cancer stage, progression and prognosis $(29,30)$. Although the significant role of cell-cycle regulation has been reported in the progression and development of tumors (29-31), the molecular mechanism of p21WAF1 regarding EPO expression in tumor progression remains to be fully explored. Results from the present study 
propose the novel conclusion that p21WAF1 may provide an important role in the proliferation, migration and invasion of bladder cancer cells that is induced by the EPO gene.

Taken together, the evidence suggests that the EPO gene induces the proliferation, G1- to S-phase cell-cycle progression, migration and invasion of bladder cancer 5637 cells. In addition, the results of the present study demonstrate the novel concept that the well-known cell-cycle inhibitor p21WAF1 is required for cell proliferation, migration and invasion through ERK1/2-mediated MMP-9 expression by stimulating NF- $\kappa \mathrm{B}$ binding activity in bladder cancer cells that express the EPO gene. In conclusion, results of the present study indicate that bladder cancer cells induced by the EPO gene are associated with proliferation, migration and invasion that contribute to the progression of bladder tumor, making it an effective target candidate of potential therapies for the prevention and treatment of malignant cells.

\section{Acknowledgements}

This research was supported by the Basic Science Research Program through the National Research Foundation of Korea (NRF), funded by the Ministry of Education, Science and Technology (2008-0062611).

\section{References}

1. Jemal A, Siegel R, Ward E, Murray E, Xu T and Thun MJ: Cancer statistics, 2007. CA Cancer J Clin 57: 43-66, 2007.

2. Black PC and Dinney CP: Bladder cancer angiogenesis and metastasis - translation from murine model to clinical trial. Cancer Metastasis Rev 26: 623-634, 2007.

3. Zachos I, Konstantinopoulos PA, Tzortzis V, Gravas S, Karatzas A, Karamouzis MV, Melekos M and Papavassiliou AG: Systemic therapy of metastatic bladder cancer in the molecular era: current status and future promise. Expert Opin Investig Drugs 19: 875-887, 2010.

4. Yun SJ, Moon SK and Kim WJ: Investigational cell cycle inhibitors in clinical trials for bladder cancer. Expert Opin Investig Drugs 22: 369-377, 2013.

5. Zaravinos A, Lambrou GI, Volanis D, Delakas D and Spandidos DA: Spotlight on differentially expressed genes in urinary bladder cancer. PLoS One 6: e18255, 2011.

6. Davies B, Waxman J, Wasan H, Abel P, Williams G, Krausz T, Neal D, Thomas D, Hanby A and Balkwill F: Levels of matrix metalloproteases in bladder cancer correlate with tumor grade and invasion. Cancer Res 53: 5365-5369, 1993.

7. Lee SJ, Cho SC, Lee EJ, Kim S, Lee SB, Lim JH, Choi YH, Kim WJ and Moon SK: Interleukin-20 promotes migration of bladder cancer cells through extracellular signal-regulated kinase (ERK)-mediated MMP-9 protein expression leading to nuclear factor $(\mathrm{NF}-\mathrm{\kappa} \mathrm{B})$ activation by inducing the upregulation of p21(WAF1) protein expression. J Biol Chem 288: 5539-5552, 2013.

8. Sato $\mathrm{H}$ and Seiki M: Regulatory mechanism of $92 \mathrm{kDa}$ type IV collagenase gene expression which is associated with invasiveness of tumor cells. Oncogene 8: 395-405, 1993.

9. Moon SK, Cha BY and Kim CH: ERK1/2 mediates TNF-alphainduced matrix metalloproteinase- 9 expression in human vascular smooth muscle cells via the regulation of NF-kappaB and AP-1: involvement of the ras dependent pathway. J Cell Physiol 198: 417-427, 2004.

10. Sato H, Kita M and Seiki M: v-Src activates the expression of 92-kDa type IV collagenase gene through the AP-1 site and the GT box homologous to retinoblastoma control elements. A mechanism regulating gene expression independent of that by inflammatory cytokines. J Biol Chem 268: 23460-23468, 1993.

11. Kumar B, Koul S, Petersen J, Khandrika L, Hwa JS, Meacham RB, Wilson S and Koul HK: p38 mitogen-activated protein kinasedriven MAPKAPK2 regulates invasion of bladder cancer by modulation of MMP-2 and MMP-9 activity. Cancer Res 70: $832-841,2010$
12. Krantz SB: Erythropoietin. Blood 77: 419-434, 1991

13. Ebert BL and Bunn HF: Regulation of the erythropoietin gene. Blood 94: 1864-1877, 1999.

14. Richmond TD, Chohan M and Barber DL: Turning cells red: signal transduction mediated by erythropoietin. Trends Cell Biol 15: 146-155, 2005.

15. Westenfelder $C$ and Baranowski RL: Erythropoietin stimulates proliferation of human renal carcinoma cells. Kidney Int 58: 647-657, 2000.

16. Lester RD, Jo M, Campana WM and Gonias SL: Erythropoietin promotes MCF-7 breast cancer cell migration by an ERK/mitogen-activated protein kinase-dependent pathway and is primarily responsible for the increase in migration observed in hypoxia. J Biol Chem 280: 39273-39277, 2005.

17. Mohyeldin A, Lu H, Dalgard C, Lai SY, Cohen N, Acs G and Verma A: Erythropoietin signaling promotes invasiveness of human head and neck squamous cell carcinoma. Neoplasia 7: 537-543, 2005

18. Fu P, Jiang X and Arcasoy MO: Constitutively active erythropoietin receptor expression in breast cancer cells promotes cellular proliferation and migration through a MAP-kinase dependent pathway. Biochem Biophys Res Commun 379: 696-701, 2009.

19. Paragh G, Kumar SM, Rakosy Z, Choi SC, Xu X and Acs G: RNA interference-mediated inhibition of erythropoietin receptor expression suppresses tumor growth and invasiveness in A2780 human ovarian carcinoma cells. Am J Pathol 174: 1504-1514, 2009.

20. Belda-Iniesta C, Perona R, Carpeno Jde C, Cejas P, Casado E, Manguan-Garcia C, Ibanez de Caceres I, Sanchez-Perez I, Andreu FB, Ferreira JA, Aguilera A, Dela PJ, Perez-Sanchez E, Madero R, Feliu J, Sereno M and Gonzalez-Baron M: Human recombinant erythropoietin does not promote cancer growth in presence of functional receptors expressed in cancer cells. Cancer Biol Ther 6: 1600-1605, 2007.

21. Liu WM, Powles T, Shamash J, Propper D, Oliver T and Joel S: Effect of haemopoietic growth factors on cancer cell lines and their role in chemosensitivity. Oncogene 23: 981-990, 2004.

22. LaMontagne KR, Butler J, Marshall DJ, Tullai J, Gechtman Z, Hall C, Meshaw A and Farrell FX: Recombinant epoetins do not stimulate tumor growth in erythropoietin receptor-positive breast carcinoma models. Mol Cancer Ther 5: 347-355, 2006.

23. Lee SJ, Lee EJ, Kim SK, Jeong P, Cho YH, Yun SJ, Kim S, Kim GY, Choi YH, Cha EJ, Kim WJ and Moon SK: Identification of pro-inflammatory cytokines associated with muscle invasive bladder cancer; the roles of IL-5, IL-20, and IL-28A. PLoS One 7: e40267, 2012.

24. Moon SK, Kim HM, Lee YC and Kim CH: Disialoganglioside (GD3) synthase gene expression suppresses vascular smooth muscle cell responses via the inhibition of ERK1/2 phosphorylation, cell cycle progression, and matrix metalloproteinase-9 expression. J Biol Chem 279: 33063-33070, 2004.

25. Sherr CJ and Roberts JM: CDK inhibitors: Positive and negative regulators of G1-phase progression. Genes Dev 13: 1501-1512, 1999.

26. Besson A, Dowdy SF and Roberts JM: CDK inhibitors: cell cycle regulators and beyond. Dev Cell 14: 159-169, 2008.

27. Fang J, Menon M, Kapelle W, Bogacheva O, Bogachev O, Houde E, Browne S, Sathyanarayana P and Wojchowski DM: EPO modulation of cell-cycle regulatory genes, and cell division, in primary bone marrow erythroblasts. Blood 110: 2361-2370, 2007.

28. Panzenböck B, Bartunek P, Mapara MY and Zenke M: Growth and differentiation of human stem cell factor/erythropoietindependent erythroid progenitor cells in vitro. Blood 92: 3658-3668, 1998.

29. Stein JP, Ginsberg DA, Grossfeld GD, Chatterjee SJ, Esrig D, Dickinson MG, Groshen S, Taylor CR, Jones PA, Skinner DG and Cote RJ: Effect of p21WAF1/CIP1 expression on tumor progression in bladder cancer. J Natl Cancer Inst 90: 1072-1079, 1998.

30. Sharia SF, Kim J, Raptidis G, Ayala GE and Lerner SP: Association of p53 and p21 expression with clinical outcome in patients with carcinoma in situ of the urinary bladder. Urology 61: 1140-1145, 2003

31. Cordon-Cardo C: Mutations of cell cycle regulators. Biological and clinical implications for human neoplasia. Am J Pathol 147: 545-560, 1995. 